\title{
Trajetória intelectual de Frederico Waldemar Lange (1911-1988) como elemento de conexão entre a ciência, a região e um projeto nacional ${ }^{1}$
}

\author{
Intellectual trajectory of Frederico Waldemar Lange (1911-1988) as a \\ connecting element among science, the region and a national project
}

\author{
DRIELLI PEYERL \\ Universidade Estadual de Campinas | UNICAMP \\ ELVIO PINTO BOSETTI \\ Universidade Estadual de Ponta Grossa | UEPG \\ EDSON ARMANDO SILVA \\ Universidade Estadual de Ponta Grossa | UEPG
}

RESUMO A figura de Frederico Waldemar Lange (1911-1988) é o centro de muitas das informações contidas no acervo do Laboratório de Paleontologia e Estratigrafia da Universidade Estadual de Ponta Grossa (UEPG). Lange reuniu de forma organizada, detalhada e meticulosa um rico material que abrange um conjunto de relações como: referências geográficas, biológicas, históricas, territoriais e regionais. A própria organização do acervo e as relações entre os diversos tipos de documentação com a História das Geociências revelam parte da trajetória intelectual do paleontólogo e seu papel no desenvolvimento dessa ciência no país.

Palavras-chave trajetória intelectual - acervo - história das geociências - paleontologia

\begin{abstract}
The person of Frederico Waldemar Lange (1911-1988) is at the center of considerable information from the collection of the Paleontology and Stratigraphy Lab of Ponta Grossa State University - UEPG (Brazil). Lange gathered, in an organized, detailed and meticulous way, a rich material which embraces a group of relations in different levels, such as geographical, biological, historical, territorial and regional references. The collection itself and the relationships among the different types of documentation from the History of Geoscience reveal part of the intellectual trajectory of this paleontologist and its role in the development of science in the country.
\end{abstract}

Key words intellectual trajectory - collection - history of geoscience - Paleontology 


\section{Introdução}

0 trabalho de Frederico Waldemar Lange representa um marco na história da Paleontologia brasileira em virtude da sua relevante contribuição para os estudos e pesquisas nessa área. Sua paixão incondicional pela Paleontologia e Geologia é evidenciada nos vários textos e atitudes que acompanharam sua notável carreira de geocientista.

Em 1996, durante o Simpósio Sul-Americano do Siluro-Devoniano, realizado na cidade de Ponta Grossa, Paraná, cujos homenageados in memoriam foram os paleontólogos Frederico Waldemar Lange e José Henrique Godoy Ciguel, a família de Lange doou parte do acervo pessoal do cientista à Universidade Estadual de Ponta Grossa (UEPG). Esse vasto material se encontra sob a guarda e conservação do Laboratório de Paleontologia e Estratigrafia do Departamento de Geociências da mesma Universidade.

Desde então, o acervo tem sido objeto de classificação, organização, estudos e pesquisas. Esta sistematização do trabalho encontra-se baseada sobremaneira em fontes primárias, algumas inéditas, tais como: cartas, relatórios, notas de viagem ou de conferências, jornais, livros, fotos, lâminas de microfósseis, coleção de conchas fósseis, revistas, artigos em diferentes línguas e outros de sua própria autoria, documentos de cunho pessoal, mapas etc.

0 acervo pessoal e os trabalhos de Lange versam sobre uma impressionante variedade de assuntos como: Geologia, Geografia, Biologia, História, Paleontologia e Micropaleontologia. Abrangendo estudos de fósseis, com destaque para a pesquisa sobre Quitinozoários e Escolecodontes (peças mandibulares de anelídeos poliquetas), os quais projetaram o paleontólogo no cenário científico nacional e internacional.

\section{A trajetória de Frederico Waldemar Lange}

Descendente de alemães, Frederico Waldemar Lange nasceu na cidade de Ponta Grossa, Paraná, no dia 23 de dezembro de 1911. Ainda jovem, passou a trabalhar na casa de comércio de fazenda, armarinhos, ferragens e secos e molhados a varejo, pertencente a seu pai Rudolph Carl Friedrich Lange (1869-1944).

Fundada em 1905 e estabelecida na Rua XV de Novembro nº 17, a casa comercial da família Lange se inseria em um meio burguês no qual as novidades europeias conquistavam a sociedade, nos moldes comerciais da época, contribuindo para a emancipação do comércio local. ${ }^{2}$

Paralelamente às atividades comerciais, Lange dedicava-se com paixão ao estudo e pesquisa em Geologia e Paleontologia, percorrendo, de motocicleta e martelo de geólogo na mão, toda a região dos Campos Gerais e adjacências, pesquisando ocorrências em seu solo. Foi o início de sua carreira como geólogo e paleontólogo.

Referenciado por outros paleontólogos e amigos vinculados à ciência a qual se dedicava em meados do século XX, Frederico Waldemar Lange teve o fator regional dos Campos Gerais e, em especial, de Ponta Grossa, fortemente aliado aos seus interesses de estudos na Paleontologia, em virtude principalmente da formação geológica do local. A região de Ponta Grossa caracteriza-se pela ocorrência de fósseis de invertebrados marinhos, que se assentam em grande parte sobre folhelhos argilosos do Devoniano, conhecidos desde o ano de 1876, por intermédio da Comissão Geológica do Império (1875), dirigida por Charles Frederick Hartt e por seu ajudante Luther Wagoner. Essa Comissão percorreu parte do Paraná, investigando a princípio a região de Guarapuava e Ponta Grossa. Nesta última encontrou alguns fragmentos fósseis, que foram determinados por Orville A. Derby e Richard Rathbun como sendo paleozoicos, provavelmente do Devoniano, de aproximadamente 400 milhões de anos. ${ }^{3}$

A região de afloramentos de rochas do Devoniano do Estado do Paraná tornou-se um dos 'laboratórios naturais' mais investigados da Paleontologia brasileira. Desde os primeiros registros no ano de 1876, os arenitos e folhelhos dessa idade geológica ocorrentes na região fisiográfica dos Campos Gerais, em conjunto com seu singular e rico conteúdo fossilífero, têm sido alvo de grande número de trabalhos que, somados, representam mais de um século de investigação científica. ${ }^{4}$ 


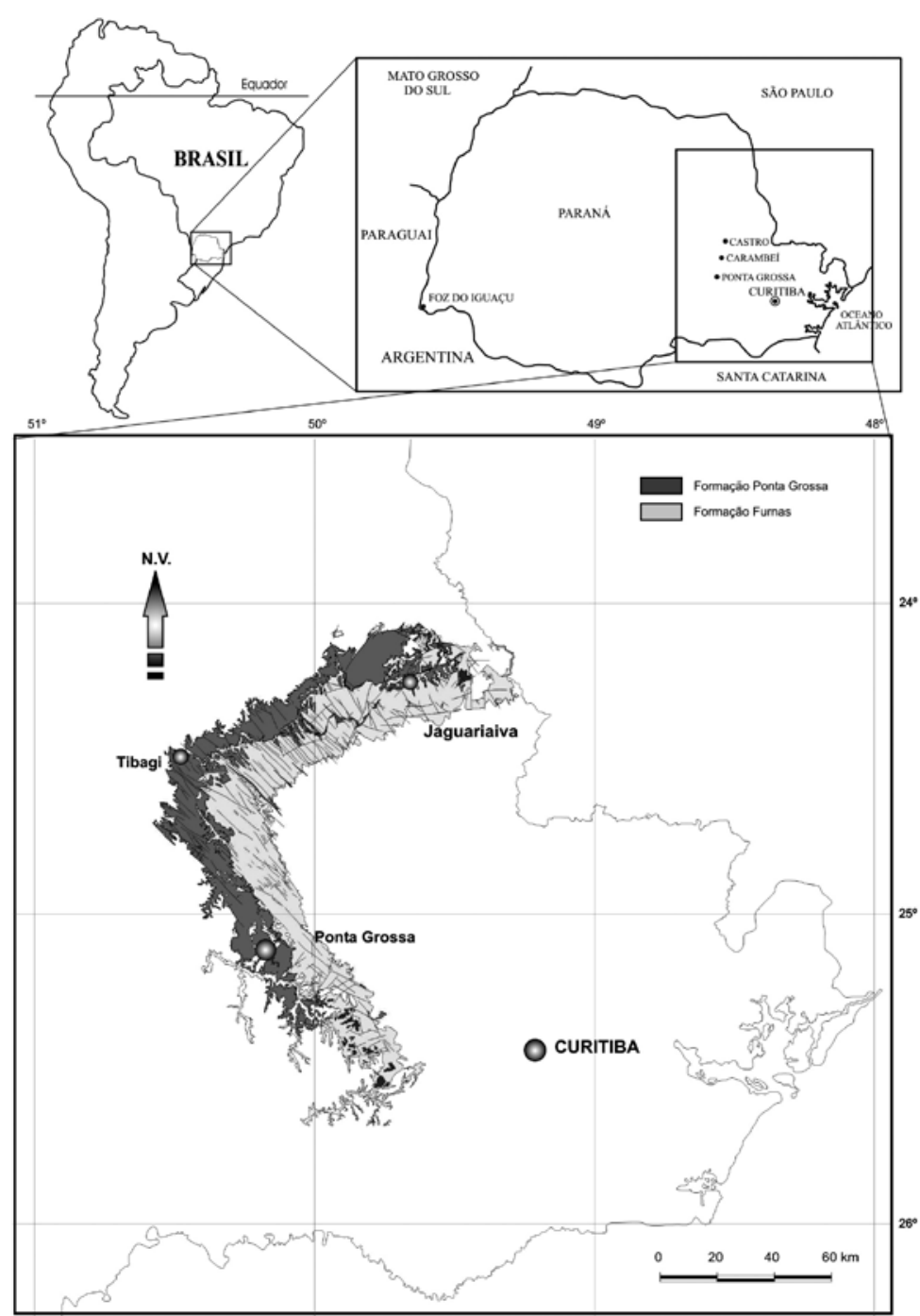

Sucessão Devoniana (Formações Furnas e Ponta Grossa) da Bacia do Paraná, Estado do Paraná, Brasil (modificado de Bosetti et. al. 2007)
No período de 1927 a 1928, Lange estudou na Escola Complementar de Comércio, em Ponta Grossa, e de 1931 a 1932, cursou Ciências Contábeis e Econômicas no Instituto Superior de Comércio, em Curitiba, no Paraná. Após sua formação continuou a trabalhar na "Casa Comercial" da família.

Em 1941, especializou-se em Geologia e Mineralogia pela Universidade do Paraná/Museu Paranaense, e assumiu o cargo de assistente da seção de Paleontologia do Museu no mesmo ano, onde permaneceu até 1946. Nos anos seguintes, entre 1947 e 1954, Lange tornou-se chefe do setor de Geologia. Em 1954, diretor do Museu Paranaense, onde permaneceu até 1955. Enquanto isso publicava trabalhos que retratavam aspectos regionais e paleontológicos do Paraná, como: Restos vermiformes do Arenito Furnas (1942); Novos fósseis devonianos do Paraná (1943); Arenitos da Vila Velha (1944); Novas localidades fossilíferas da série Itararé (1944); Anelídeos poliquetas dos folhelhos devonianos do Paraná (1947); Novos microfósseis devonianos do Paraná (1949); Polychaete annelids from the Devonian of Paraná (1949); e Um novo escolecodonte dos Folhelhos Ponta Grossa (1950).

Se, por um lado, os trabalhos publicados o projetavam nacionalmente no campo da Paleontologia, por outro, ele se esforçava para constituir um grupo de intelectuais na cidade de Ponta Grossa. Foi um dos grandes colaboradores e doadores de materiais fósseis para a constituição do Museu dos Campos Gerais (1950). Membro do Centro Cultural Euclides da Cunha (1948), por intermédio do qual o Museu de início foi administrado, tornou-se conselheiro da Seção de Geologia e Paleontologia do mesmo. Participou também da fundação da Sociedade Ponta-grossense de Amadores de Astronomia (SPAA). Lange participou ativamente, durante algum tempo, do Conselho Fiscal dessa Sociedade, que teve participação ativa na construção dos estudos relacionados à astronomia na região. ${ }^{5}$

Descrevendo afloramentos e coletando material, Lange tinha como base de estudos a monografia de John M. Clarke, que se destacou por descrever "A nova trilobita Dalmanites gonzaganus; embora essa classificação tivesse posteriormente sido revista pelo próprio Clarke (1913)". ${ }^{6}$ Este foi, segundo Lange, o primeiro fóssil especificamente identificado no Paraná.

Em 1955, encerrou seu trabalho como diretor do Museu Paranaense, no qual contribuiu com a organização e construção dos estudos de Geociências no Estado, para iniciar seu trabalho na Petrobras.

Em 1954, Lange coordenou um projeto que culminou com a edição comemorativa de um volume sobre a Paleontologia do estado do Paraná, em relação à comemoração do centenário do estado, pontuando cronologicamente descobertas científicas dentro da área de Paleontologia. Tal trabalho teve como colaboradores grandes 
cientistas, paleontólogos e geólogos, estudiosos e pesquisadores da ciência na época, como: Karl Beurlen, Kenneth E. Caster, Elias Dolianiti, Richard Kräusel, Jordano Maniero, Josué Camargo Mendes, Sergio Mezzalira e Friedrich Wilhelm Sommer.

Entre os anos de 1950 e 1955, Lange também integrou e posteriormente atuou como professor de Geologia e Paleontologia da Faculdade Católica de Filosofia em Curitiba. Neste mesmo período, já auxiliava os geólogos do Conselho Nacional do Petróleo (CNP), determinando a posição estratigráfica de fósseis encontrados em amostras de campo de regiões do Paraná?

0 Conselho Nacional do Petróleo (CNP) havia sido criado em 1938 para avaliar os pedidos de pesquisa e lavra de jazidas de petróleo. 0 decreto que instituiu o CNP também declarou de utilidade pública o abastecimento nacional do produto e regulou as atividades de importação, exportação, transporte, distribuição, comércio e derivados, bem como o funcionamento da indústria do refino no país. As possíveis descobertas de jazidas passaram a ser consideradas como patrimônio da União. ${ }^{7}$ A criação do CNP marca o início de uma nova fase da história do petróleo e da Paleontologia no Brasil.

\section{A criação da Petrobras}

“Em 1950, os círculos políticos e econômicos do país concentravam a sua atenção no pleito presidencial". ${ }^{10}$ Dirigindo-se aos trabalhadores de modo direto e emocional, defendendo o nacionalismo econômico, a industrialização e a necessidade de ampliar as leis trabalhistas, Getúlio Vargas venceu as eleições presidenciais nessa época.

Com o retorno de Vargas ao poder, o país retomou o desenvolvimento sob o patrocínio do Estado tanto por meio de subsídios como da implantação de uma infraestrutura necessária ao crescimento do capital privado. Ao capital estrangeiro ficaram as indústrias de bens de consumo. Dessa maneira:

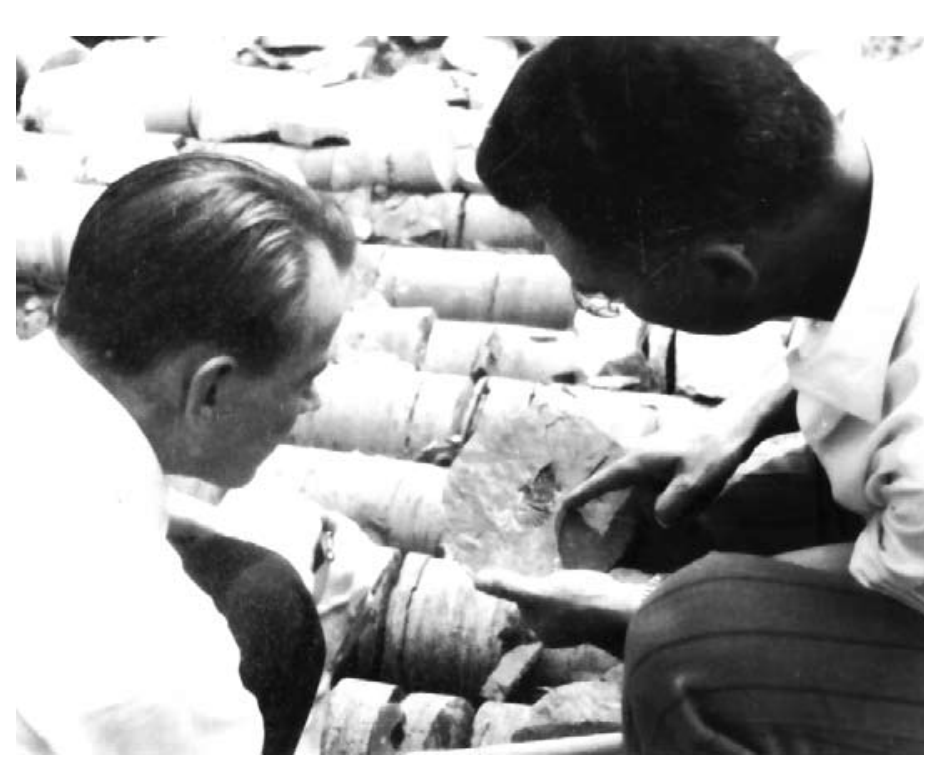

Frederico Waldemar Lange (à direita) analisando testemunhos de sondagem. Década de 1950. ${ }^{9}$

O retorno de Vargas ao poder no início de 1951 representou afirmação de um projeto, claramente exposto na campanha eleitoral pelo então candidato, centrado na industrialização e na modernização agrícola, tendo como ênfase a produção para mercado interno e no qual se reservava ao Estado importante papel de articulador e estimulador. A opção desenvolvimentista do governo era afirmada em quase todas as oportunidades no discurso presidencial e, com menos intensidade, no de seu Ministro da Fazenda, Horácio Lafer; não raro, permeavam-no apelos nacionalistas e favoráveis à melhoria na distribuição de renda. Não havia, entretanto, objeções maiores ao capital estrangeiro: a exemplo da implantação da grande siderurgia à época do Estado Novo, com capital e tecnologia estrangeiros, entendia-se que estes seriam bem-vindos ao país. ${ }^{11}$

0 segundo governo de Vargas caracterizou-se pelo nacionalismo e pelo populismo. A industrialização apoiada em grandes investimentos do Estado brasileiro voltou a ser vista como condição para o progresso. 
Esse modelo de desenvolvimento pretendido por Vargas dividiu a sociedade brasileira. De um lado estavam os nacionalistas que tinham como líder a figura de Getúlio Vargas e defendiam a ideia de um Estado interventor da economia, investindo em áreas estratégicas, como petróleo, siderurgia, transportes e comunicações. Do outro, estavam seus adversários, chamados de entreguistas, defensores de uma economia sem a interferência do Estado.

Os debates entre os nacionalistas e seus adversários intensificaram-se quando a questão do petróleo foi levantada. Estudantes, sindicalistas, parte dos militares - liderados pelo general Newton Estillac Leal - e os políticos do Partido Trabalhista do Brasil (PTB) e do Partido Comunista Brasileiro (PCB) defendiam que o Brasil deveria ter uma indústria própria de extração e refino de petróleo. Para isso criaram e lideraram uma campanha nacional com o slogan 0 Petróleo é Nosso. A oposição, liderada por políticos da União Democrática Nacionalista (UDN) e por militares antigetulistas, era favorável à exploração do petróleo nacional por empresas estrangeiras que já operavam no Brasil, como Esso, Texaco, Shell etc. ${ }^{12}$

A disputa chegou ao final com a vitória dos nacionalistas. Assim, em 3 de outubro de 1953, foi criada a Petrobras, uma empresa estatal que tinha o monopólio da extração, do refino e do transporte marítimo do petróleo brasileiro.

Essas tensões na política nacional se refletiram diretamente na vida profissional de Frederico Waldemar Lange, pois as pesquisas para a indústria do petróleo geraram um avanço no conhecimento da Estratigrafia das bacias sedimentares brasileiras. Especialistas estrangeiros foram contatados para iniciar trabalhos na área da Micropaleontologia e reorganizar os antigos núcleos do Conselho Nacional do Petróleo, transformando-os em laboratórios regionais.

Logo em seguida, uma equipe de brasileiros começou a colaborar, unindo seu trabalho ao dos estrangeiros. Surgiram assim novos métodos de trabalho e aprendizagem sobre a Paleontologia, junto a grandes nomes que consagram essa ciência. ${ }^{13} \mathrm{~A}$ trajetória intelectual de Lange está entrelaçada a esses avanços tecnológicos e científicos.

A princípio a Petrobras estabeleceu três laboratórios regionais no país, nos municípios de: Belém - PA, Salvador - BA e Ponta Grossa - PR, para pesquisas, exploração e procura de regiões petrolíferas.

Ao iniciar as suas atividades exploratórias a Petrobras contava então com apenas um Laboratório de Paleontologia, localizado em Belém, incumbido da análise das amostras principalmente da Bacia do Amazonas. ${ }^{14}$ Após alguns anos, o ponto da pesquisa concentrou-se na instalação do laboratório regional do município de Ponta Grossa, denominado Departamento de Exploração da Bacia Sedimentar do Paraná (DEBSP), em Ponta Grossa. Criado oficialmente em março de 1955, vários fatores favoreceram as instalações do DEBSP no município, dentro os quais sua localização geográfica, ponto de entroncamento ferroviário com o restante do país.

Em 15 de março de 1955, Lange iniciou o que culminaria em sua carreira profissional dentro da Petrobras. Atuando como paleontólogo no DEBSP, realizando atividades relacionadas à sua área até 1958.

Em 1 de março de 1958, Lange foi designado técnico sênior. Após um mês foi então designado Geólogo-Chefe do DEBSP, onde permaneceu até 13 de julho de 1959. Transferiu-se para o Rio de Janeiro, para assumir o cargo de superintendente geral adjunto do Departamento de Exploração do Rio de Janeiro.

Nesse período, de 1952 a 1960 Lange publicou: Revisão da fáunula do Folhelho Passinho (1952); Chitinozoários do folhelho Barreirinha, devoniano do Pará (1952); Paleontologia e Evolução dos seres vivos (1953); Estratigrafia e idade geológica da Série Tubarão (1954); Paleontologia do Paraná (1954); Nota preliminar sobre a fáunula do Arenito El Carmen (1955); Aspectos econômicos da exploração do petróleo no Brasil (1959) e Basin study approach to oil evaluation of Paraná miogeosyncline of South Brazil (1960).

Durante a realização de suas pesquisas e com o conhecimento adquirido, Lange tornou-se uma das prováveis pessoas a assumir o cargo máximo de exploração da Petrobras, o de chefe de Exploração do DEPEX, substituindo Walter K. Link.

A substituição de Link por Lange ocorreu em 01 de janeiro de 1961, assumindo a chefia do Departamento de Exploração (DEPEX). No período em que permaneceu como chefe, realiza funções administrativas, propondo instalações de outros laboratórios nos distritos, e também estudos mais profundos principalmente na região do Amazonas. 
Em março de 1962, Lange foi dispensado do cargo de chefe do DEPEX, e retomou suas atividades no mês seguinte como paleontólogo no DEPEX/Rio. Assim, dedicou-se mais aos trabalhos paleontológicos nos laboratórios regionais e aos relatórios do setor de Paleontologia como um todo. De agosto de 1962 a novembro de 1965, Lange ficou encarregado do Laboratório de Paleontologia do DESBP em Ponta Grossa.

No ano de 1965, Lange foi designado para supervisor do Laboratório de Paleontologia do antigo DESBP, agora denominado de Departamento de Exploração do Sul (DESUL). Realizou atividades de separação e processamento de amostras do Paleozoico da Bacia do Amazonas, preparação de lâminas, estudos sistemáticos, descrição e ilustração de microfósseis.

Em novembro de 1967, foi transferido para a Divisão de Exploração (DIVEX/RJ) para chefiar o Setor de Paleontologia, no qual realiza a preparação e organização do setor, bem como relatórios de viagem às unidades para implantação e supervisão do Setor de Estratigrafia (SESTRA) e nos distritos regionais de exploração.

No ano de 1968, foi nomeado chefe do Setor de Estratigrafia na Região Exploradora do Nordeste (RENOR), Região de Produção do Nordeste (RPNE), Região de Produção da Bahia (RPBA) e Departamento de Exploração do Sul (DESUL).

Em 1969, como chefe do SESTRA, desempenhou atividades de supervisão dos trabalhos do Setor no DIVEX e nas unidades; programando e controlando projetos; realizou também uma revisão estratigráfica da Bacia do Paraná.

Na década de 1960 publicou outros importantes trabalhos como: Subdivisão bioestratigrafica e revisão da coluna siluro-devoniana da Bacia do Baixo Amazonas (1967); The Devonian Paraná Basin (1967); Bioestratigraphic subdivision and correlation of the Devonian in Paraná Basin (1967) e Les "Leiofusidae" Eisenack (1967).

Na década de 1970 publica ainda: Silurian of Brazil (1972) e Stratigraphy of the Cretaceous sedimentary basins of Brazil (1975).

Na transição da década de 1969 para 1970, realizou uma 'especialização' por intermédio do Curso de Atualização em Técnicas Exploratórias (CATEX II), de 7 a 30 de julho de 1969. De 5 a 28 de julho de 1971 participou do CATEX III. Essa especialização era ofertada pela parceria com a Petrobras, Serviço Nacional de Aprendizagem Industrial e American Association of Petroleum Geologists.

Assim, Lange permaneceu como chefe do Setor de Estratigrafia, até a sua aposentadoria por tempo de serviço em outubro de 1972.

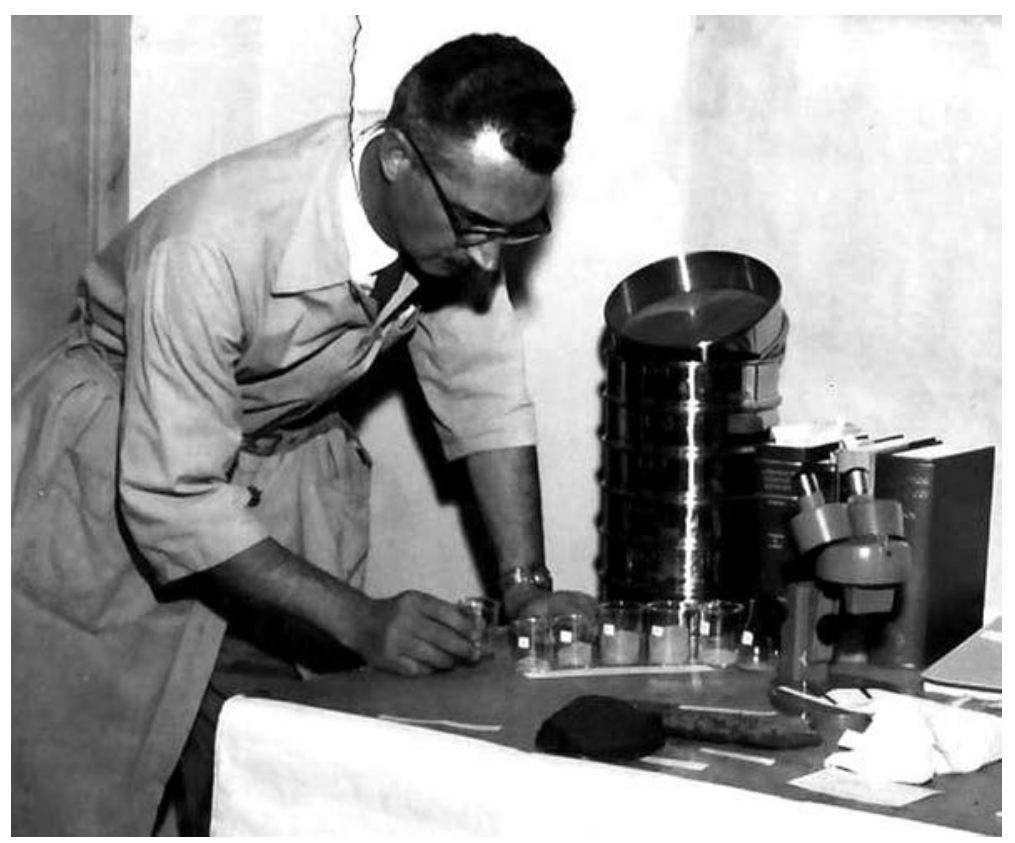

Frederico Waldemar Lange. Década de $60 .{ }^{15}$
Foi no ano de 1972 que Lange encerrou sua participação como cientista e profissional da Petrobras. Após alternar cargos e de estar sempre contribuindo em vários setores para uma boa estruturação e funcionalidade da empresa, Lange sempre almejou que seu trabalho rendesse bons frutos para a pesquisa e para a ciência.

Em 1972, então aposentado da Petrobras, Lange continuou sua participação como estudioso e pesquisador das geociências no país. Nesse mesmo ano tornou-se coordenador suplente do Léxico Estratigráfico Internacional, subcomissão encarregada da parte do Brasil.

Em março de 1975, atendendo a um convite da Mineração Colorado Ltda, 
colaborou na qualidade de geólogo sênior e como encarregado de projetos de pesquisas de minerais do país, permanecendo nesse cargo até janeiro de 1986.

No dia 16 de junho de 1988, Lange falece de enfisema pulmonar, na cidade do Rio de Janeiro.

Por todo seu trabalho científico desenvolvido e em respeito a sua paixão pela Paleontologia, por muitas vezes Lange foi homenageado tanto em vida como in memoriam. Muito do seu trabalho e dos dados pessoais aqui levantados, tais como 0 ano de seu nascimento, vida acadêmica, só foi possível por meio da pesquisa realizada em seu acervo pessoal. Publicou 22 trabalhos.

Além disso, a relevância dos trabalhos de Lange o projetou muito além do seu pequeno laboratório, instalado inicialmente em sua residência na cidade de Ponta Grossa. Seu nome se tornaria referência nacional e internacional. Também foi o pesquisador que mais se concentrou em estudar a fauna fóssil marinha de Ponta Grossa desde os primeiros estudos no final do século XIX. Essas publicações marcaram o desenvolvimento da ciência paleontológica e a região de Ponta Grossa tornou-se referência obrigatória em todos os livros que tratam da história desta ciência.

\section{Considerações finais}

0 paleontólogo Frederico Waldemar Lange (1911-1988), além de se visto como um grande cientista, também foi criador, inovador, hábil administrador e profundo conhecedor da Paleontologia do Devoniano brasileiro.

Com toda a sua dedicação e paixão pelas Geociências tornou-se um dos pesquisadores mais respeitados do seu meio. As obras publicadas, a ciência construída, o trabalho intensivo e sua extrema dedicação ainda permanecem vivos nos dias atuais. Muito de seus escritos ainda são utilizados como base para estudos de Paleontologia e Micropaleontologia.

A importância dos trabalhos paleontológicos e estratigráficos se Lange o projetou muito além do seu pequeno laboratório, instalado inicialmente em sua residência em Ponta Grossa. Tornar-se-ia mundialmente famoso e respeitado, com frequentes citações em diversos livros e artigos de universidades norte-americanas e europeias.

Dessa forma, o acervo expressa as tensões de sua trajetória de vida. Uma trajetória que pode ser vista como um nó em uma trama mais ampla, pois uma biografia expressa as tensões de sua época. ${ }^{16} \mathrm{Na}$ trajetória de Lange destacamos três dessas forças: a Paleontologia como a ciência estudada por Lange, a região a qual contribui para 0 seu desenvolvimento cultural e econômico e a Petrobras como um projeto nacional.

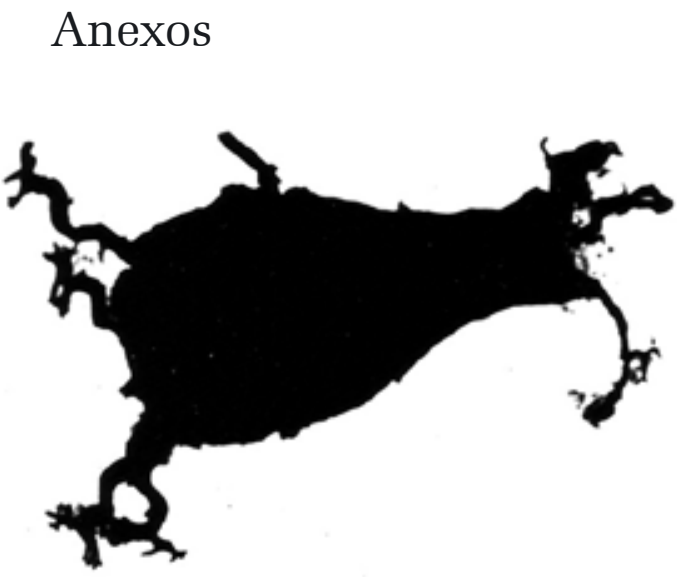

Figura 1: Quitinozoário devoniano ${ }^{17}$

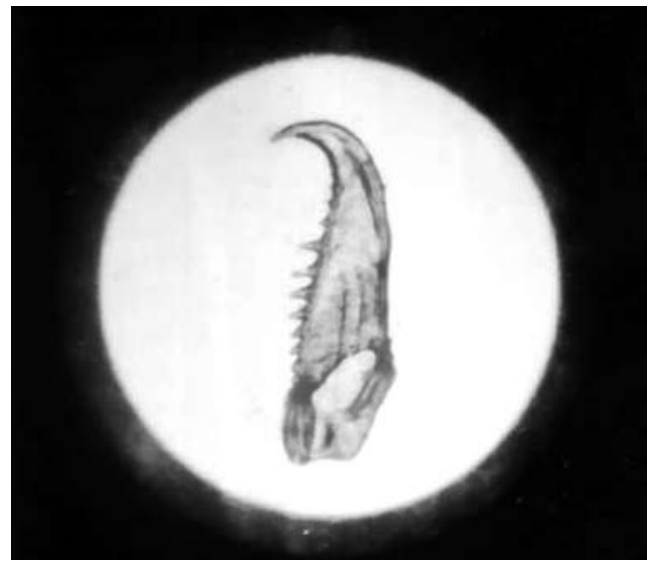

Figura 2: Escolecodonte ${ }^{18}$ 


\section{Agradecimentos}

À família de Frederico Waldemar Lange (1911-1988). À dra. Silvia Fernanda de Mendonça Figueirôa (UNICAMP) e ao dr. Luiz Padilha Quadros (Petrobras) pelas sugestões e críticas. Ao prof. M. Sc. Fernando Pilatti e ao prof. M. Sc. Olavo Soares pelas informações concedidas. À Fundação de Amparo à Pesquisa do Estado de São Paulo (Proc. № 2010/14857-2) e ao CNPq (480427/2007-0) e CNPq (401796/2010-8) pelo suporte financeiro.

\section{Notas e referências bibliográficas}

Drielli Peyerl é historiadora e doutoranda do Programa de Pós-Graduação em Ensino e História de Ciências da Terra (EHCT), da Universidade Estadual de Campinas (UNICAMP) e bolsista FAPESP (Proc. № 2010/14857-2). E-mail: driellipeyerl@gmail.com.

Elvio Pinto Bosetti é paleontólogo e Professor Docente do Departamento de Geociências e do Mestrado em Gestão do Território da Universidade Estadual de Ponta Grossa (UEPG). Doutor em Ciências. E-mail: bosetti@pesquisador.cnpq.br.

Edson Armando Silva é professor adjunto do Departamento de História da Universidade Estadual de Ponta Grossa (UEPG). Doutor em História. E-mail: edasilva@ uepg.br.

1 Mais informações em PEYERL, Drielli. A trajetória do paleontólogo Frederico Waldemar Lange (1911-1988) e a História das Geociências. 116 f. Dissertação (Mestrado em Gestão do Território) - Universidade Estadual de Ponta Grossa, 2010.

2 LANGE, Francisco Lothar Paulo. Família Lange: genealogia, notas biográficas, fatos contemporâneos. Curitiba: F.L.P. Lange, 2003.

3 LANGE, Frederico Waldemar. Paleontologia do Paraná. Curitiba: Comissão do Centenário do Paraná, 1954. p. 4.

4 BOSETTI, Elvio Pinto. Paleontologia do Devoniano dos Campos Gerais. In: MELO, Mário Sérgio; MORO, Rosemeri Segeein; GUIMARÃES, Gilson Burigo. Patrimônio natural dos Campos Gerais. Ponta Grossa, Paraná: Ed. UEPG, 2007. p. 33-47.

5 PEYERL, op. cit., p. 36.

6 LANGE, op. cit., p. 5.

7 A posição estratigráfica dos fósseis é importante porque estabelece a correspondência entre duas ou mais camadas de rochas que contenham o mesmo material fóssil. A isso se dá o nome de biocorrelação que é regida pelos bio-horizontes da primeira aparição à última presença de fósseis característicos, em diferentes secções estratigráficas.

$8 \quad$ Histórico da empresa Petrobras. Disponível em: <www2.petrobras.com.br>. Acesso em: 1 ago. 2008.

9 FREDERICO Waldemar Lange (à direita) analisando testemunhos de sondagem. Década de 1950. Fotografia. Acervo pessoal de Frederico Waldemar Lange (1911-1988). Laboratório de Paleontologia e Estratigrafia da Universidade Estadual de Ponta Grossa (UEPG). Caixa: 22.

10 VICTOR, Mário. A batalha do petróleo brasileiro. 3. ed. Rio de Janeiro: Editora Civilização Brasileira S. A. 1993.

11 FONSECA, Pedro Cezar Dutra; MONTEIRO, Sérgio Marley Modesto. Credibilidade e populismo no Brasil: a política econômica dos governos Vargas e Goulart. Rev. Bras. Econ., v. 59, n. 2, p. 215-243, 2005.

12 VICTOR, Mário. A batalha do petróleo brasileiro. 3. ed. Rio de Janeiro: Editora Civilização Brasileira S. A., 1993.

13 CASSAB, Rita de Cássia Tardin. Histórico das pesquisas paleontológicas no Brasil. In: CARVALHO, Ismar de Souza (Org.). Paleontologia. Rio de Janeiro: Interciência, 2000. p. 13-17.

14 Instalações DEBSP, 1968. Relatório. Acervo Frederico Waldemar Lange (1911-1988). UEPG. Cx. 35. P. 01.

15 FREDERICO Waldemar Lange - Laboratório de Paleontologia - DEBSP, Ponta Grossa. Década de 60. Fotografia. Acervo de Frederico Waldemar Lange (19111988). Laboratório de Paleontologia e Estratigrafia da Universidade Estadual de Ponta Grossa (UEPG). Caixa: 52.

16 BOURDIEU, Pierre. A ilusão biográfica. In: AMADO, Janaína; FERREIRA, Marieta Moraes. Usos e abusos da história oral. Rio de Janeiro: Fundação Getúlio Vargas, 1996. p. 183-220.

17 QUITINOZOÁRIOS devonianos. Fotografia. Acervo pessoal de Frederico Waldemar Lange (1911-1988). Laboratório de Paleontologia e Estratigrafia da Universidade Estadual de Ponta Grossa (UEPG). Caixa: 25.

18 ANELÍDEOS poliquetas (Escolecodontes). Fotografia. Acervo pessoal de Frederico Waldemar Lange (1911-1988). Laboratório de Paleontologia e Estratigrafia da Universidade Estadual de Ponta Grossa (UEPG). Caixa: 25.

[Recebido em maio de 2009, aprovado para publicação em setembro de 2010] 